\title{
Application of Neural Network for Concrete Carbonation Depth Prediction
}

\author{
Daming Luo, Ditao Niu, and Zhenping Dong \\ School of Civil Engineering, Xi'an University of Architecture and Technology
}

\begin{abstract}
Concrete carbonation is one of the most significant causes of deterioration of reinforced concrete structures in atmospheric environment. However, current models based on the laboratory tests cannot predict carbonation depth accurately. In this paper, the BP neural network is optimized by the particle swarm optimization (PSO) algorithm to establish the model of the length of the partial carbonation zone for concrete. After simulation training, the improved model is applied to a concrete bridge for carbonation depth prediction. The results show that the improved model, which has faster a convergence rate, has a good ability in predicting the length of the partial carbonation zone of the reinforced concrete, and the predicted value matches the field-measured value very well, which provides scientific guidance to durability design, assessment, and life prediction for concrete structures.
\end{abstract}

Keywords: carbonation depth, concrete, durability, neural network.

\section{INTRODUCTION}

As one of the most commonly used building materials, concrete has been widely used in industrial and civil construction, transportation, water conservancy, port, and other projects; its durability problems have become an important part of global sustainable development discussions and great importance is attached to it in domestic and international academics and engineering. It is indicated in early 2009 by the American Society of Civil Engineers (American Society of Civil Engineers Report, 2009) report that the average health status of the nation's infrastructure still remains at the $D$ level, and the maintenance costs would be more than 2.2 trillion US dollars over the next 5 years. The investigation (Glasser, Marchand, \& Samson, 2008; Niu, 2003; Shang, Yi, \& Song, 2012) showed that the durability problem of existing concrete structures in China is also very serious. In the Disciplinary Development Strategy Report edited by National Natural Science Foundation Council in 2006, Professor W. Jin (Jin \& Niu, 2011) clearly pointed out, "To carry out the durability and lifecycle cost optimization study for concrete structures is a major issue related to people's livelihood."

Reinforcement corrosion is the major cause of the durability deterioration of reinforced concrete structures. Carbonation can reduce the alkaline of concrete, thereby making it lose the protection of steel, which is a prerequisite for concrete reinforcement corrosion in the common atmospheric environment. Therefore, it is of great importance to study the prediction model of concrete carbonation depth, which provides scientific guidance to the durability design, assessment, and life prediction for concrete structures (Niu, 2003). Scholars all over the world (Liu et al., 2004; Lu \& Liu, 2008; Papadakis, Vayenas, \& Fardis, 1991; Pu, Niu, \& Dong, 1999; Steffens, Dinkler, \& Ahrens, 2002) have raised a number of mathematical models to predict the concrete carbonation depth. However, most of these models are based on laboratory tests, and the prediction results are a relatively serious error from the field-measured value. Although some models took into account laboratory and field conditions, the calculated results also have a large difference from the test value due to the complexity of the influencing factors. Hence, it is difficult to establish a calculation model that can accurately reflect various factors of concrete carbonation. In view of this, seeking a new research approach that is different from the classical theory is much more necessary.

\section{THE PSO-BP NEURAL NETWORK DESIGN}

With strong nonlinear mapping capabilities, the artificial neural network can achieve nonlinear input and output between the sample data through self-learning of neurons without any assumptions and models (Xu \& Wu, 2002; Yuan, 1999). Hence, it is appropriate to use the neural network method to solve those engineering problems that find it difficult to establish precise mathematical models but easy to collect samples (such as concrete carbonation) with advanced testing methods (Parthiban et al., 2005; Rafiq, Vayenas, \& Fardis, 2001). In this paper, BP neural network, which is optimized by PSO algorithm, effectively overcomes its defects of slow convergence, unstable solution, liability to fall into local minima, and initial value 
sensitivity, and is used to predict carbonation depth of concrete, and reasonable results are obtained.

\subsection{Standard PSO algorithm}

The speed-location search model is adopted in the standard PSO algorithm (Kennedy, Eberhart et al., 1995; Li et al., 2005). First, randomly initialize $m$ particles and make them evenly distributed in the feasible solution space to constitute the initial population; each particle represents a potential solution to the optimization problem. Then randomly initialize a speed for each particle, according to the objective function, calculate each particle's fitness value to measure the level of the pros and cons of particles. In every step of the iteration, the particle will track its own optimal value (on behalf of the particle's own cognitive level) and the current global optimal value of the population (on behalf of social cognitive level), and search the optimal solution step by step. The detailed steps are as follows.

In the D-dimensional solution space, there are $m$ particles, the ith particle position is $X_{\mathrm{i}}=\left(X_{\mathrm{i} 1}, X_{\mathrm{i} 2} \cdots, X_{\mathrm{iD}}\right)$, and velocity is $v_{\mathrm{i}}=\left(v_{\mathrm{i} 1}, v_{\mathrm{i} 2}, \cdots, v_{\mathrm{iD}}\right), \quad i=1,2, \cdots, m$. Put $x_{\mathrm{i}}$ into the objective function and get their fitness, denote the optimal position searched by the ith particle $p_{\mathrm{i}}=\left(p_{\mathrm{i} 1}, p_{\mathrm{i} 2}, \cdots, p_{\mathrm{iD}}\right)$, and the optimal location search by the whole particle swarm is $p_{\mathrm{g}}=\left(p_{\mathrm{g} 1}, p_{\mathrm{g} 2}, \cdots, p_{\mathrm{gD}}\right)$. The update operation of particle state is as follows:

$$
\begin{gathered}
V_{\mathrm{id}}(t+1)=W V_{\mathrm{id}}(t)+c_{1} r_{1}\left(p_{\mathrm{id}}-X_{\mathrm{id}}(t)\right) \\
+c_{2} r_{2}\left(p_{\mathrm{gd}}-X_{\mathrm{id}}(t)\right) \\
X_{\mathrm{id}}(t+1)=X_{\mathrm{id}}(t)+V_{\mathrm{id}}(t+1),
\end{gathered}
$$

where $i=1,2, \cdots, m ; d=1,2, \cdots, D, r_{1}, r_{2}$ are the random number in [0,1]; $c_{1}, c_{2}$ are acceleration factors, usually taken as $c_{1}=c_{2}=2$; $w$ is the inertia factor that usually ranged in 0.1 0.9; $V_{\text {id }} \in\left[-V_{\max }, V_{\max }\right], V_{\text {max }}$ is a constant.

\subsection{The PSO-BP neural network design}

In view of the defects of BP neural network and the superior performance of PSO algorithm in unconstrained nonlinear function optimization that are usually used to search for the global optimal solution, the advantages of the PSO algorithm and BP algorithm are combined to train the neural network in this paper. First, train the network with PSO algorithm and then refine the search in small scale with $\mathrm{BP}$ algorithm to find a mapping law between the input and output that is implicit in the structure and the interconnection weights of the neural network.

When the BP network is improved by PSO algorithm, the position vector of the particle swarm is composed by the weights and thresholds of the trained BP network. Random function can produce more than one particle, that is, produce groups of neuron connection weights and thresholds of BP network and then form the particle swarm. After that, PSO algorithm is used to search for the best position that coordinates the optimal connection weights and thresholds of the BP network, so that the mean square error indicator (the fitness value) as follows is made to a minimum:

$$
J=\frac{1}{N} \sum_{\mathrm{i}=1}^{N} \sum_{\mathrm{j}=1}^{\circ}\left(y_{\mathrm{ij}}^{\mathrm{d}}+y_{\mathrm{ij}}\right)^{2},
$$

where $N$ is the number of training samples, $O$ is the number of neurons in the network output layer, $y_{i j}^{d}$ and $y_{i j}$ are the desired output value, and the actual output value of the ith sample in the jth output neuron, respectively.

The PSO-BP neural network algorithm may be formulated as the following steps:

Step 1: normalize the inputting data matrix and the target data matrix;

Step 2: initialize the network topology and the population parameters;

Step 3: take each vector as a set of weights of the new network that is to be formed and evaluate and calculate the fitness value of the individuals that is composed by the network weights and thresholds;

Step 4: determine whether it is less than the maximum error or less than the minimum number of iterations; if it is so, transfers directly to Step 6; otherwise, go to Step 5;

Step 5: update the location of the particle velocity with the PSO algorithm and generate a new population, then get the $P_{\text {best }}$ and $G_{\text {best }}$ of the particles, return to Step 3; and

Step 6: take the global best particle as the optimal weights and thresholds of BP neural network and train the BP neural network.

\section{ESTABLISHMENT OF PREDICTION MODEL FOR CONCRETE CARBONATION DEPTH}

\subsection{Accelerated carbonation tests}

Accelerated carbonation tests using ordinary Portland cement (with admixture of $15 \%$ ) are taken under the guidance of Standard for test methods of long-term performance and durability of ordinary concrete GB/ T50082-2009 (GB/T50082-2009, 2010) in the artificial climate laboratory and concrete carbonation tank. Some test results are used as sample data for neural network training.

\subsection{The selection of the network input factors}

When concrete structure expose to atmospheric environment, the $\mathrm{pH}$ value of concrete gradually 
decreases from outside to inside, and the concrete carbonation process can be divided into three regions: completely carbonized area, partial carbonation zone, and uncarbonated zone. According to the corrosion mechanism of steel bars in concrete, when $\mathrm{pH}>11.5$, the steel bars are in passive state. With the development of carbonation, the $\mathrm{pH}$ near the reinforcement gradually decreased, while the steel corrosion rate is gradually increasing. When $\mathrm{pH}<9$, reinforcement corrosion-rate remains unchanged. Therefore, it is of more practical significance to focus on partial carbonation zone which $9<\mathrm{pH}<11.5$ (Jiang \& Zhang, 1999). The length of the partial carbonation zone can be calculated as follows (Zhang et al., 2003):

$$
X_{\mathrm{hc}}=1.017 \times 10^{4}(0.7-R H)^{1.82} \sqrt{\frac{W / C-0.31}{C}}
$$

Since this prediction model is established for $9<\mathrm{pH}<11.5$ parts of partial carbonation zone, and existing experimental study shows that the $\mathrm{CO}_{2}$ concentration as well as the carbonation time had no influence on partial carbonation zone length, the model will choose the water-cement ratio, W/C, cement content $\mathrm{C}$, and relative humidity $\mathrm{RH}$ as the input factors.

\subsection{Training for concrete carbonation depth prediction model}

According to the existing theories, feed-forward neural networks with only one hidden layer can approximate any nonlinear relationship with any precision (Yuan, 1999). In this paper, three-layer neural network is used for concrete carbonation depth prediction model, and the topology is shown in Figure 1.

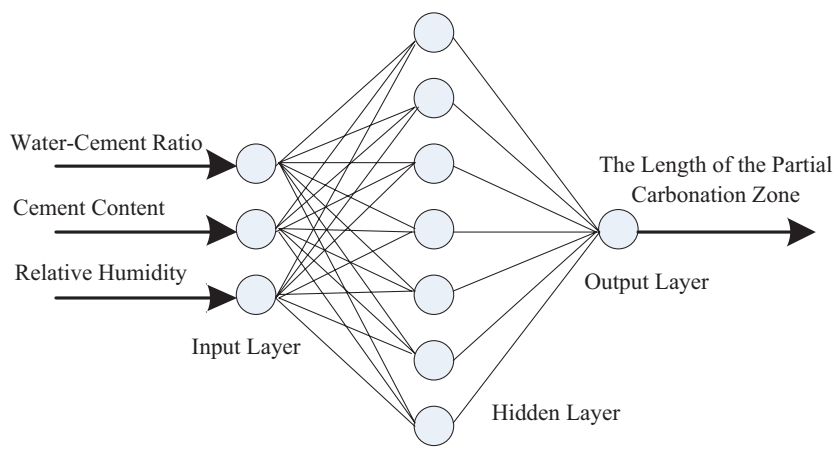

Figure 1. Topology of the prediction model for the length of the partial carbonation zone.

Neuron nodes of hidden layer are generally determined by the empirical formula:

$$
I=\sqrt{m+n}+a
$$

or

$$
I=\sqrt{0.43 m n+0.12 n^{2}+2.54 m+0.77 n+0.35+0.51},
$$

where $m, n$ are the number of input nodes and output nodes, respectively; $a$ is taken as a constant between 1 and 10 (Zhuo, 2011).

After a number of simulation experiments, the node number of the input layer, the hidden layer, and the output layer of the BP neural network were finalized, respectively, as 3,7 , and 1 . After input value and output value normalization and neural network training, noise is added into output value to promote its generalization ability. Since most of the global search work has been completed by PSO algorithm, the learning rate of the BP algorithm should be as small as possible to perform a refined search. Figure 2 shows the convergence curve of neural network training based on BP algorithm and PSO-BP algorithm.

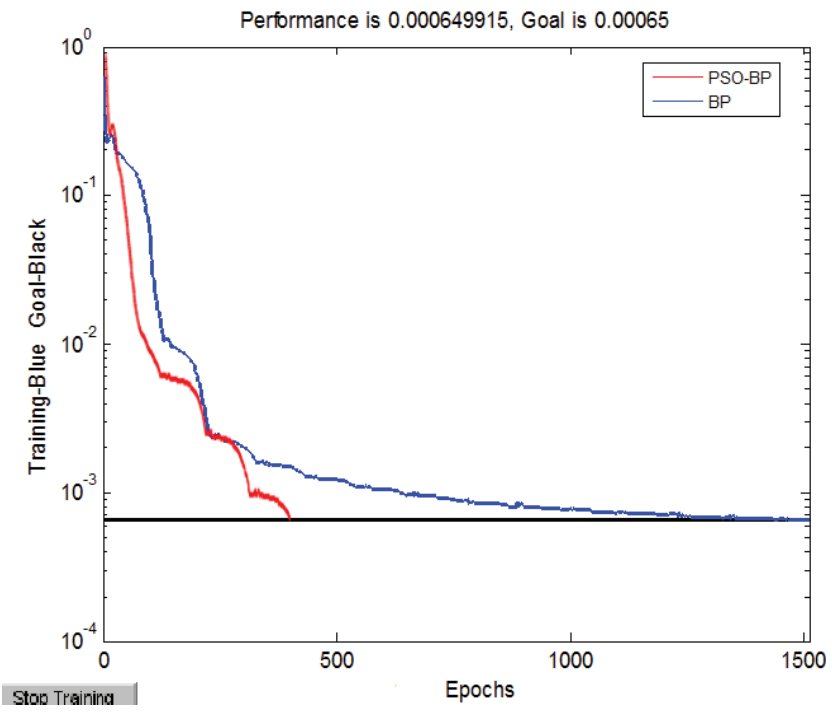

Figure 2. BP algorithm and PSO-BP algorithm convergence curve.

It can be seen from Figure 2 that the PSO-BP algorithm converges much more quickly than BP algorithm after a few steps of iteration. Since the adaptive learning adjustment of the weights and threshold of BP neural network is carried out in accordance with the previous error function value until one gets the target error value in the next step, while the optimized weights and thresholds in the PSO algorithm is close to the final result and the adjustable range of error is very small, the PSO global optimization algorithms can overcome the defects of the BP algorithm and speed the convergence in training the network. The simulation results of network training for sample data are shown in Table 1.

\section{METHODOLOGY APPLICATIONS}

\subsection{Example application}

A bridge in Shaanxi Province of China is $130 \mathrm{~m}$ high. The left half-bridge is $668.00 \mathrm{~m}$ in length, and 
Table 1. Simulation results of network training for sample data.

\begin{tabular}{|c|c|c|c|c|c|c|c|c|c|}
\hline \multirow[t]{2}{*}{$\begin{array}{l}\text { Test } \\
\text { No. }\end{array}$} & \multicolumn{3}{|c|}{ Input factors } & \multirow{2}{*}{$\begin{array}{c}\text { Expectations } \\
\text { Length } \\
(\mathrm{mm})\end{array}$} & \multicolumn{2}{|c|}{$\begin{array}{l}\text { Predicted value } \\
\text { by BP network }\end{array}$} & \multicolumn{2}{|c|}{$\begin{array}{c}\text { Predicted value } \\
\text { by PSO-BP network }\end{array}$} & \multirow[t]{2}{*}{ Remark } \\
\hline & W/C & $\begin{array}{c}C \\
\left(\mathrm{~kg} / \mathrm{m}^{3}\right)\end{array}$ & $\begin{array}{l}\mathrm{RH} \\
(\%)\end{array}$ & & $\begin{array}{c}\text { Length } \\
(\mathrm{mm})\end{array}$ & $\begin{array}{l}\text { Relative } \\
\text { error (\%) }\end{array}$ & $\begin{array}{l}\text { Length } \\
(\mathrm{mm})\end{array}$ & $\begin{array}{l}\text { Relative } \\
\text { error (\%) }\end{array}$ & \\
\hline 1 & 0.5 & 400 & 0.3 & 41.8 & 42.159 & 0.8 & 42.128 & 0.8 & Simulation \\
\hline 2 & 0.5 & 400 & 0.35 & 32.8 & 32.121 & -2.1 & 32.849 & 0.1 & Simulation \\
\hline 3 & 0.5 & 400 & 0.4 & 24.8 & 25.09 & 1.2 & 25.109 & 1.2 & Simulation \\
\hline 4 & 0.5 & 400 & 0.45 & 17.8 & 17.938 & 0.8 & 17.909 & 0.6 & Simulation \\
\hline 5 & 0.5 & 400 & 0.5 & 11.8 & 12.819 & 8.6 & 11.874 & 0.6 & Simulation \\
\hline 6 & 0.5 & 400 & 0.53 & 8.8 & 9.2027 & 4.6 & 9.0141 & 2.4 & Simulation \\
\hline 7 & 0.5 & 400 & 0.56 & 6.2 & 5.4836 & -11.6 & 5.9344 & -4.3 & Simulation \\
\hline 8 & 0.5 & 400 & 0.6 & 3.4 & 2.4061 & -29.2 & 3.3362 & -1.9 & Simulation \\
\hline 9 & 0.5 & 400 & 0.63 & 1.8 & 1.2651 & -29.8 & 1.9078 & 6.0 & Simulation \\
\hline 10 & 0.5 & 400 & 0.66 & 0.6 & 0.67217 & 12.0 & 0.6305 & 5.1 & Simulation \\
\hline 11 & 0.4 & 350 & 0.5 & 8.7 & 9.4189 & 8.3 & 8.4111 & -3.3 & Simulation \\
\hline 12 & 0.43 & 350 & 0.5 & 10.1 & 10.435 & 3.3 & 10.305 & 2.0 & Simulation \\
\hline 13 & 0.47 & 350 & 0.5 & 11.6 & 11.474 & -1.2 & 11.391 & -1.8 & Simulation \\
\hline 14 & 0.5 & 350 & 0.5 & 12.7 & 12.124 & -4.5 & 12.217 & -3.8 & Simulation \\
\hline 15 & 0.54 & 350 & 0.5 & 13.9 & 12.984 & -6.6 & 13.341 & -4.0 & Simulation \\
\hline 16 & 0.57 & 350 & 0.5 & 14.8 & 13.762 & -7.0 & 14.207 & -4.0 & Simulation \\
\hline 17 & 0.6 & 350 & 0.5 & 15.6 & 14.77 & -5.3 & 15.092 & -3.3 & Simulation \\
\hline 18 & 0.67 & 350 & 0.5 & 17.4 & 17.549 & 0.9 & 17.545 & 0.8 & Simulation \\
\hline 19 & 0.70 & 350 & 0.5 & 18.1 & 18.266 & 0.9 & 17.939 & -0.9 & Simulation \\
\hline 20 & 0.75 & 350 & 0.5 & 19.3 & 19.937 & 3.3 & 19.837 & 2.8 & Simulation \\
\hline 21 & 0.6 & 200 & 0.6 & 5.9 & 5.8811 & -0.3 & 5.9188 & 0.3 & Simulation \\
\hline 22 & 0.6 & 250 & 0.6 & 5.2 & 5.4185 & 4.2 & 5.3112 & 2.1 & Simulation \\
\hline 23 & 0.6 & 300 & 0.6 & 4.8 & 4.9998 & 4.2 & 5.022 & 4.6 & Simulation \\
\hline 24 & 0.6 & 350 & 0.6 & 4.4 & 4.6395 & 5.4 & 4.6205 & 5.0 & Simulation \\
\hline 25 & 0.6 & 400 & 0.6 & 4.1 & 4.3416 & 5.9 & 4.2482 & 3.6 & Simulation \\
\hline 26 & 0.6 & 450 & 0.6 & 3.9 & 4.1041 & 5.2 & 4.0965 & 5.0 & Simulation \\
\hline 27 & 0.6 & 500 & 0.6 & 3.7 & 3.9219 & 6.0 & 3.7502 & 1.4 & Simulation \\
\hline 28 & 0.6 & 550 & 0.6 & 3.5 & 3.7889 & 8.3 & 3.3817 & -3.4 & Simulation \\
\hline 29 & 0.6 & 600 & 0.6 & 3.4 & 3.6986 & 8.8 & 3.24 & -4.7 & Simulation \\
\hline 30 & 0.6 & 650 & 0.6 & 3.3 & 3.6451 & 10.5 & 3.2317 & -2.1 & Simulation \\
\hline
\end{tabular}

the right half-bridge is $698.00 \mathrm{~m}$. The main bridge is $55+4 \times 100+55 \mathrm{~m}$ long with prestressed steelconcrete continuous composite beams. The left and the right bridge approach are $5 \times 30 \mathrm{~m}$ and $6 \times 30 \mathrm{~m}$, respectively, with prestressed concrete continuous box girder. The bridge pier construction was completed in April 2007, and the box girder was completed in December. The bridge was opened to traffic on September 28, 2008.

\subsection{Results and discussion}

The predicted results of concrete carbonation depth of concrete composite beams, concrete box girder, and concrete piers of the main bridge and approach are shown in Table 2.
The results show that the BP neural network model optimized by PSO algorithm can greatly reduce the average relative error and improve the predictive accuracy, and the optimized model can predict the length of the partial carbonation zone more quickly and accurately. PSO-BP neural network can find the hidden mapping rule between the input and output of the neural network and the interconnection weights. Besides, the PSO-BP algorithm training error is convergent, and almost does not fall into local minimum or oscillate. That is, the prediction model of the length of the partial carbonation zone based on PSO-BP neural network has a high precision and authentic predicted value that can reflect the field situation. 
Table 2. Predicted results of carbonation depth.

\begin{tabular}{|c|c|c|c|c|c|c|c|c|c|}
\hline \multirow[t]{2}{*}{ No. } & \multicolumn{3}{|c|}{ Input factors } & \multirow{2}{*}{$\begin{array}{c}\text { Expectations } \\
\text { Length } \\
(\mathrm{mm})\end{array}$} & \multicolumn{2}{|c|}{$\begin{array}{l}\text { Predicted value } \\
\text { by BP network }\end{array}$} & \multicolumn{2}{|c|}{$\begin{array}{l}\text { Predicted value } \\
\text { by PSO-BP network }\end{array}$} & \multirow[t]{2}{*}{ Remark } \\
\hline & W/C & $\begin{array}{c}C \\
\left(\mathrm{~kg} / \mathrm{m}^{3}\right)\end{array}$ & $\begin{array}{l}\mathrm{RH} \\
(\%)\end{array}$ & & $\begin{array}{l}\text { Length } \\
(\mathrm{mm})\end{array}$ & $\begin{array}{l}\text { Relative } \\
\text { error (\%) }\end{array}$ & $\begin{array}{l}\text { Length } \\
(\mathrm{mm})\end{array}$ & $\begin{array}{l}\text { Relative } \\
\text { error (\%) }\end{array}$ & \\
\hline 1 & 0.51 & 500 & 0.43 & 18.8 & 19.9348 & 6.0 & 19.2199 & 2.2 & Prediction \\
\hline 2 & 0.55 & 680 & 0.43 & 17.6 & 16.7207 & -5.0 & 16.9907 & -3.5 & Prediction \\
\hline 3 & 0.75 & 500 & 0.52 & 13.3 & 13.8403 & 4.1 & 13.3806 & 0.6 & Prediction \\
\hline 4 & 0.75 & 500 & 0.65 & 1.3 & 1.4304 & 10.0 & 1.3104 & 0.8 & Prediction \\
\hline 5 & 0.55 & 680 & 0.65 & 0.8 & 0.9021 & 12.8 & 0.8221 & 2.8 & Prediction \\
\hline
\end{tabular}

\section{CONCLUSION}

Since the particle swarm algorithm is an optimization process under the guidance of individual learning and social information-sharing principles, and the BP algorithm completes its optimization process in accordance with the specified anti-gradient descent trajectory, the routes of the two processes do not coincide. The optimizing of PSO algorithm on BP neural network can greatly shorten the training time and improve the prediction accuracy.

The factors affecting concrete carbonation depth are complex and with interactions among them. This article only focus on the nonlinear relationship among the cement content, water-cement ratio, relative humidity, and the length of the partial carbonation zone with $9<\mathrm{pH}<11.5$. Further research work can be performed to get a more comprehensive analysis of various factors and improve prediction accuracy.

The accumulation of field-measured value and laboratory results is very important to the artificial neural networks for the establishing of concrete carbonation depth prediction model. Due to the fact that the sample data is limited, the type of concrete, the strength of concrete, the thickness of concrete cover, and other factors are not considered in this article. It is necessary for additional work to be undertaken for a further in-depth study.

\section{ACKNOWLEDGMENTS}

This work was supported by National Natural Science Foundation of China, Grant No. 51278403. In addition, this work presented herein was conducted in the State Key Laboratory of Architecture Science and Technology in West China at Xi'an University of Architecture \& Technology. The authors gratefully acknowledge the support that has made this laboratory and its operation possible.

\section{REFERENCES}

American Society of Civil Engineers. (2009).

Report Card for America's Infrastructure
[EB/OL]. (2009-01-29) [2009-02-20]. Retrieved from http://www.asce.org/reportcard/

GB/T50082-2009. (2010). Standard for test methods of long-term performance and durability of ordinary concrete. Beijing, China: China building industry Press.

Glasser, F. P., Marchand, J., \& Samson, E. (2008). Durability of concrete-Degradation phenomena involving detrimental chemical reactions. Cement and Concrete Research, 38(2), 226-246.

Jiang, L. X., \& Zhang, Y. (1999). Analysis and calculation of the length of half-carbonated zone in concrete. Indstrial Construction, 29(1), 4-7.

Jin, W., \& Niu, D. (2011). The state-of-the-art on durability and life-cycle design theory of engineering structures. Engineering Mechanics, S2, 31-37.

Kennedy, J., \& Eberhart, R. (1995). Particle swarm optimization. Proceedings of IEEE international conference on neural networks, Perth, WA. 1942-1948.

Li, D., Lu, D., Kong, X., \& Wu, G. (2005). Implicit curves and surfaces based on BP neural network. Journal of Information and Computational Science, 2(2), 259-271.

Liu, R., Lu, C., \& Lei, L. (2004). Study on durability of modern prestressed concrete structure in carbonation. Industrial Construction, 34, 69-72.

Lu, C., \& Liu, R. (2008). Carbonation depth prediction of pre-stressed concrete based on artificial neural network. Journal of Harbin Institute of Technology, 10(40), 1649-1651.

Niu, D. (2003). Durability and life prediction of concrete structures. Beijing, China: Science Press.

Papadakis, V. G., Vayenas, C. G., \& Fardis, M. N. (1991). Fundamental modeling and experimental investigation of concrete carbonation. $\mathrm{ACl}$ Materials Journal, 88(4), 363-373.

Pu, Y., Niu, D., \& Dong, Z. (1999). Random model of predicting the carbonated concrete depth [j]. Industrial construction, 29(9), 41-45.

Rafiq, M. Y., Vayenas, C. G., \& Fardis, D. J. (2001). Neural network design for engineering 
applications. Computers and Structures, 79(17), $1541-1552$.

Shang, H. S., Yi, T. H., \& Song, Y. P. (2012). Behavior of plain concrete of a high water-cement ratio after freeze-thaw cycles. Materials, 5(9), 1698-1707.

Steffens, A., Dinkler, D., \& Ahrens, H. (2002).

Modeling carbonation for corrosion risk prediction of concrete structures. Cement and Concrete Research, 32(6), 935-941.

Thirumalai, P., Ravi, R., Parthiban, G. T., Srinivasan, S., Ramakrishnan, K. R., \& Raghavan, M. (2005). Neural network analysis for corrosion of steel in concrete. Corrosion Science, 47(7), 1625-1642.
Xu, D., \& Wu, Z. (2002). Analysis and design for system based on MATLAB 6. X-neural network. Xi'an, China: Xi'an University of Science and Technology.

Yuan, C. (1999). Artificial neural networks and its application. Beijing, China: Tsinghua University Press.

Zhang, Y., et al. (2003). Durability of concrete structures. Shanghai, China: Shanghai Scientific \& Technical Publishers.

Zhuo, J. (2011). The applications of MATLAB software in mathematical modeling. Beijing, China: Beihang University Press. 